\title{
Fermentation of primary alcohols and diols and pure culture of syntrophically alcohol-oxidizing anaerobes
}

\author{
Barbara Eichler and Bernhard Schink \\ Fakultät für Biologie, Universität Konstanz, Postfach 5560, D-7750 Konstanz, Federal Republic of Germany
}

\begin{abstract}
Ethanol, propanol, ethylene glycol, 1,2-propanediol, 1,2-butanediol, acetoin, diacetyl, and 2,3-pentanedione were used as substrates for enrichment and isolation of alcohol-oxidizing fermentative bacteria. Diacetyl and 2,3pentanedione proved to be highly toxic. With the other substrates, various kinds of bacteria could be isolated which were assigned to three different metabolic groups: (i) homoacetogenic bacteria, and (ii) bacteria forming propionate as reduced end product were isolated from freshwater sources; (iii) bacteria disproportionating acetoin and 1,2-diols to acids and primary alcohols were isolated from marine sediments. The latter oxidized primary alcohols to fatty acids in the presence of hydrogen-oxidizing partners. Syntrophically ethanol-oxidizing cocultures enriched with primary alcohols could be separated with 1,2-diols as substrates into an alcohol-oxidizing organism and a hydrogenoxidizing homoacetogen. The pathways of alcohol conversion in the disproportionating isolates were studied in detail. Growth experiments as well as enzymological studies demonstrated that acetoin and 1,2-diols were degraded via acetaldehyde which was also an intermediate in syntrophic oxidation of primary alcohols. The environmental importance of the various metabolic types isolated was assessed by most-probable-number enumerations.
\end{abstract}

Key words: Anaerobic alcohol degradation - Syntrophic metabolism - Diols - Aldehydes - Acetoin - Homopropionate fermentation - Homoacetogenesis

Primary alcohols are important fermentation products formed during anaerobic degradation of organic matter. Anaerobic oxidation of alcohols to the corresponding fatty acids can only occur if the reducing equivalents derived can be transferred to suited electron acceptors. Sulfate-reducing bacteria can couple the oxidation of primary alcohols with concomitant reduction of sulfate to sulfide (Postgate and Campbell 1966). In the absence of sulfate, ethanol can be condensed with acetate to form butyrate (Bornstein and Barker 1948), or carbon dioxide is reduced to form either acetate (Wieringa 1940; Braun et al. 1981; Eichler and Schink 1984) or propionate (Samain et al. 1982; Laanbroek et al. 1982; Schink 1984) as reduced end product. The reduction of protons to form hydrogen as reduced fermentation product is an endergonic reaction under standard conditions which needs to be coupled with a hydrogen-oxidizing reac-

Offprint requests to $: \mathrm{B}$. Schink tion keeping the hydrogen partial pressure low (Thauer et al. 1977). An ethanol-oxidizing syntrophic association of this kind called "Methanobacillus omelianskii" (Barker 1936) was separated to an ethanol-oxidizing "S-organism" and a hydrogen-oxidizing methanogen, strain M.o.H. (Bryant et al. 1967). The former organism could be grown in pure culture with pyruvate as substrate, but was lost lateron. Some sulfate-reducing bacteria can cooperate with hydrogen-oxidizing methanogens in a similar manner as the "Sorganism" if sulfate is absent (Bryant et al. 1977).

1,2-Diols such as ethylene glycol are fermented by pure cultures of Clostridium glycolicum (Gaston and Stadtman 1963) or Aerobacter aerogenes (Abeles and Lee 1961; Toraya et al. 1979) to the corresponding fatty acid and primary alcohol, e.g., acetate and ethanol. Enzymological studies revealed that the diol was transformed to an aldehyde which underwent subsequent disproportionation to ethanol and acetate (Toraya et al. 1979). A similar metabolic pathway was recently suggested for Pelobacter venetianus, a strict anaerobe isolated with polyethylene glycol (Schink and Stieb 1983) and for a similar organism isolated with 2,3butanediol, P. carbinolicus (Schink 1984). Both Pelobacter species were able to grow with primary alcohols in syntrophic coculture with hydrogen-oxidizing anaerobes in a manner similar to the "S-organism" in "Methanobacillus omelianskii".

The present study was started to investigate whether other substrates similar to those mentioned above can be used to enrich for bacteria able to degrade primary alcohols. It is demonstrated that at least in some cases aldehydeyielding substrates such as 1,2-diols, acetoin, or 2,3butanediol are suited substrates for growth of "S-organism"like anaerobes in pure culture.

\section{Materials and methods}

Sources of organisms

The following strains were enriched and isolated from sediment and sewage sludge samples:

- Strains Ko1.2Pd1, KoEtOH1 and Gö1.2Pd1 from anoxic digestor sludge of municipal sewage plants at Konstanz and Göttingen, FRG.

- Strains AS1.2Bd1, WoETOH1 and LiAc1 from anoxic mud of freshwater ditches near Konstanz and Hannover, FRG.

- Strains GraEtOH11 and Ma1.2Bd1 from sediments of Canal Grande and Rio Marin, Venice, Italy, and strain CuAc1 from marine sediment taken near Cuxhaven, FRG. 
Methanospirillum hungatei strain $\mathrm{M} 1 \mathrm{~h}$ was isolated from digested sludge of the sewage plant at Göttingen, FRG. Acetobacterium woodii strain NZva16 was kindly provided by A. Tschech, Konstanz, FRG.

\section{Cultivation and chemical analyses}

All procedures for cultivation and isolation as well as all methods for chemical analysis were essentially the same as described earlier (Widdel and Pfennig 1981; Schink and Pfennig 1982). Carbonate-buffered, sulfide-reduced freshwater or saltwater mineral media with low phosphate content contained trace element solution SL9 (Tschech and Pfennig 1984) and vitamin solution (Pfennig 1978). The $\mathrm{pH}$ was 7.2 to 7.4. Agar shake dilution series were used for purification (Pfennig 1978). Aldehydes were idenfied by gas chromatography (Schink and Pfennig 1982).

\section{Enumeration}

Numbers of alcohol-degrading anaerobes were estimated in freshwater sediment and sewage sludge samples by the most probable number method (American Public Health Association 1969). Ethanol, propanol, butanol, or ethylene glycol was used as substrate at $10 \mathrm{mmol} \cdot 1^{-1}$ concentration. After $3-4$ weeks of incubation at $28^{\circ} \mathrm{C}$, turbidity and fermentation products were assayed.

\section{Continuous culture experiments}

In some cases, growth experiments were carried out in homocontinous culture. Mineral medium under $\mathrm{N}_{2} / \mathrm{CO}_{2}$ mixture $(80 \% / 20 \%)$ with 1,2 propanediol, ethylene glycol, or acetaldehyde as substrates passed a peristaltic pump and a gassed dropping vial right on the top of the $500 \mathrm{ml}$ culture vessel. The headspace above the culture liquid was small $(<20 \mathrm{ml})$ and the cell suspension was transported out of the vessel by a low gas pressure $(10 \mathrm{mbar})$ which balanced the hydrostatic pressure exerted by the height difference between culture surface and outflow level $(10 \mathrm{~cm})$. This construction allowed to remove the used medium by a tube reaching $5 \mathrm{~cm}$ deep into the liquid without passing a continuous gas stream through the headspace.

\section{Enzymes}

Crude cell extracts for determination of enzymatic activities were prepared in a nitrogen-gassed French pressure cell at 1,400 bar. After subsequent removal of non-destroyed cells at $10,000 \times g$ for $15 \mathrm{~min}$, enzymatic reactions were measured at $25^{\circ} \mathrm{C}$ in a Zeiss PM4 spectrophotometer using rubberstoppered $\mathrm{N}_{2}$-gassed cuvettes.

Alcohol dehydrogenase and acetate kinase activity were determined according to Bergmeyer (1974). Aldehyde dehydrogenase activity was measured via reduction of benzylviologen (Odom and Peck 1981). Phosphate acetyltransferase activity was determined according to Oberlies et al. (1980). Conversion of 1,2-diols to the respective aldehydes was measured either by determination of aldehyde formation with time (Abeles 1969; Schütz and Radler 1984) or by measuring diol dehydratase activity as aldehyde-dependent alcohol formation (Toraya et al. 1979). Protein contents of crude cells extracts were determined by a micro-biuret method (Goa 1953; Kuenen and Veldkamp 1972).

\section{Results}

\section{Enrichments and isolations}

Enrichment cultures with $50 \mathrm{ml}$ freshwater or saltwater medium containing $10 \mathrm{mmol} \cdot 1^{-1}$ of either ethanol, propanol, ethylene glycol, 1,2-propanediol, 1,2-butanediol, acetoin, diacetyl, or 2,3-pentanedione as substrates were inoculated each with $5 \mathrm{ml}$ freshwater or marine mud samples from different sources. Enrichment cultures with diacetyl and pentanedione did not produce any gas. Both diacetyl and pentanedione at $10 \mathrm{mM}$ concentration completely inhibited gas formation in enrichment cultures with acetoin as substrate. In enrichment cultures with ethanol, propanol, ethylene glycol, 1,2-propanediol, 1,2-butanediol and acetoin, methane production started after $2-5$ days and ceased after $2-3$ transfers. Pure cultures were isolated in agar shake series. Bacteria formed white to yellow lens-shaped colonies in the agar. Colonies were resuspended in mineral medium and again diluted in agar shake series. Purity was checked by microscopical control and by growth tests in complex medium in which only the isolated cell types could be observed. Finally, 8 out of 32 new isolates were chosen for further characterization. All isolates were mesophilic with temperature optima at $30-34^{\circ} \mathrm{C}$ and temperature limits at 15 and $40^{\circ} \mathrm{C}$. The $\mathrm{pH}$ optima were around $\mathrm{pH} 6.5-7.5$.

\section{Characterization of new isolates}

The source of inoculation material and the enrichment medium rather than the substrate used for enrichment determined to a high extent the metabolic type of the respective isolates. Although there were minor differences within each group with respect to substrate utilization, all isolates were assigned to three different metabolic groups on the basis of substrate utilization and product formation.

Group I. Strains Ko1.2Pd1, Gö1.2Pd1, and AS1.2Bd1 were isolated from freshwater sources with 1,2-propanediol or 1,2-butanediol as substrates. They were nonesporeforming motile rods which stained weakly Gram-positive, 1.0$1.3 \times 2.0-3.5 \mu \mathrm{m}$ in size, with slightly pointed ends. They usually used methanol, ethanol, propanol, butanol, several diols, acetoin, glycerol, malate, lactate, pyruvate, glucose and fructose as substrates, and grew autotrophically with formate or hydrogen/carbon dioxide. 3,4,5Trimethoxybenzoate was demethylated to gallic acid, betaine to glycine. The results of substrate tests are summarized in Table 1. Degradation products of primary alcohols and 1,2-diols were the corresponding fatty acids and acetate. With all other substrates, acetate was the only fermentation product. Thus, the described three strains exhibited physiological properties typical of homoacetogenic bacteria. As an exception, strain Gö1.2Pd1 formed propanol and propionate in equal amounts and traces of propionaldehyde when grown with 1,2-propanediol.

Group II. Strains WoEtOH1, KoEtOH1 and LiAc1 were isolated from freshwater sources with ethanol or acetoin, respectively. They were Gram-negative motile rods, $0.6-$ $0.7 \times 1.0-3.3 \mu \mathrm{m}$ in size, with rounded ends. Spores were not formed.

Optimal growth occurred with freshwater mineral medium. Ethanol, propanol, butanol, 2,3 butanediol, acetoin, lactate and pyruvate were used as growth substrates; none 
Table 1. Substrates tested for growth of new isolates

\begin{tabular}{llll}
\hline Substrate & Group I & Group II & Group III \\
\hline $\mathrm{H}_{2} / \mathrm{CO}_{2}$ & + & - & - \\
Formate & + & - & - \\
Methanol & $+(2 / 5)^{\mathrm{b}}$ & - & - \\
3,4,5-Trimethoxybenzoic acid & + & - & - \\
Ethanol & $+(3 / 5)$ & $+(3 / 4)$ & - \\
Propanol $^{\mathrm{a}}$ & $+(3 / 5)$ & $+(1 / 4)$ & - \\
Butanol $^{\mathrm{a}}$ & $+(3 / 5)$ & $+(1 / 4)$ & - \\
Ethylene glycol & $+(4 / 5)$ & $+(2 / 4)$ & $+(4 / 5)$ \\
Ethanolamine & - & + & + \\
Choline & - & - & + \\
Betaine & + & - & - \\
1,2-Propanediol & $+(4 / 5)$ & - & $+{ }^{\mathrm{a}}$ \\
1,2-Butanediol & $+(2 / 5)$ & - & $+{ }^{\mathrm{a}}$ \\
2,3-Butanediol & + & + & $+(4 / 5)$ \\
Acetoin & + & + & + \\
Glycerol & + & - & $+{ }^{\mathrm{a}}(4 / 5)$ \\
Malate & $+(3 / 5)$ & - & - \\
Lactate & $+(4 / 5)$ & + & - \\
Pyruvate & $+(3 / 5)$ & + & - \\
Glucose & $+(2 / 5)$ & - & - \\
Fructose & $+(3 / 5)$ & - & - \\
\hline
\end{tabular}

Growth tests were carried out in duplicates in defined media Substrate concentrations were $2 \mathrm{mM}$ with sugars, $5 \mathrm{mM}$ with methanol and trimethoxybenzoic acid, and $10 \mathrm{mM}$ with all others

a $5 \mathrm{mM}$ acetate added as carbon source

b These substrates were not degraded by all strains of the respective group; the values in brackets give the number of positive strains over all strains tested

of the strains grew autotrophically with formate or $\mathrm{H}_{2} / \mathrm{CO}_{2}$ (Table 1). Primary aliphatic alcohols were fermented to the corresponding fatty acid and propionate; all other substrates were degraded to acetate and propionate.

Group III. Strains Ma1.2Bd1 and CuAc1 were isolated from marine sources with 1,2-butanediol or acetoin as substrates. They were nonsporeforming, Gram-negative, motile rods, $0.5-1.0 \times 1.0-2.5 \mu \mathrm{m}$ in size, with rounded ends (Fig. 1). Optimal growth occurred in marine mineral medium. Ethylene glycol, ethanolamine, choline, 1,2-propanediol, 1,2butanediol, 2,3-butanediol, acetoin, and glycerol were the only substrates used. Neiher primary alcohols nor sugars were degraded, and none of the strains was able to grow autotrophically (Table 1). With 1,2-diols, the corresponding alcohol and fatty acid were formed in nearly equal amounts. Glycerol was transformed in a similar manner to 1,3-propanediol and 3-hydroxypropionate. Ethanol and acetate were formed during degradation of ethanolamine, choline, 2,3-butanediol, and acetoin. With choline, methylamines were formed which were identified by their characteristic odor. The amounts of products formed agreed with complete stoichiometric substrate degradation within $3-10 \%$ deviation.

\section{Separation and reassociation of syntrophic cocultures}

From enrichments with marine sediments and primary alcohols as substrates, binary mixed cultures were isolated which grew in homogeneous colonies in the agar shake tubes and could not be separated by further dilution. These cultures (GraEtOH1 and GraProp1) formed acetate and

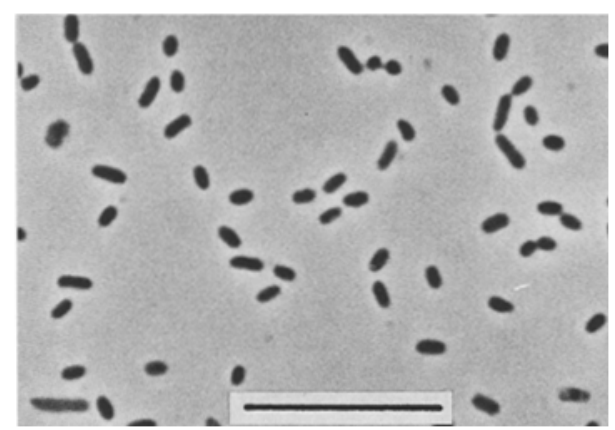

Fig. 1. Phase contrast photomicrograph of strain Ma1.2Bd1 (Group III). Bar equals $10 \mu \mathrm{m}$

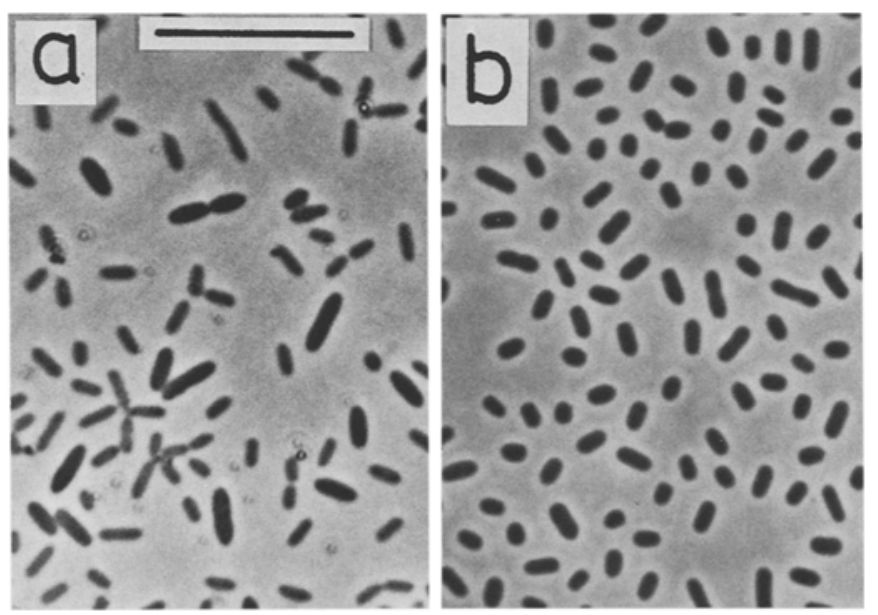

Fig. 2a, b. Phase contrast photomicrograph of marine isolates with ethanol as substrate. a Mixed culture GraEtOH1 consisting of Acetobacterizm woodii and a syntrophic alcohol oxidizing bacterium. b Pure culture of alcohol oxidizing strain GraEtOH11 isolated from GraEtOH1 with ethylene glycol as substrate. Bar equals $10 \mu \mathrm{m}$ for both panels

the respective fatty acids from primary aliphatic alcohols. Microscopically, two cell types could be differentiated: the larger cell type appeared similar to Acetobacterium sp., the smaller one similar to the new isolates grouped in group III (Fig. 2a). If these mixed cultures were subjected to agar shake dilutions with 1,2-propanediol as substrate, two different types of colonies were formed which could be grown in separate pure cultures with 1,2-propanediol and small amounts of acetate. The larger cell type was identified by its typical substrate utilization spectrum and product formation pattern as belonging to the species Acetobacterium similar to the isolates assigned to group I except that it was unable to grow with primary alcohols. The smaller cell type (strains GraEtOH11 and GraProp11) exhibited substrate utilization and product formation patterns similar to those strains assigned to group III and resembled those bacteria also morphologically (Fig. 2b). Mixed cultures of both types degraded primary aliphatic alcohols syntrophically to acetate and the respective fatty acid as the original cocultures did. Coupling of strain GraEtOH11 with Methanospirillum hungatei allowed growth and syntrophic methanogenic oxidation of primary aliphatic alcohols to the respective fatty acids (Table 2). 
Occurrence of aldehydes as intermediates

\section{of 1,2-diol degradation}

Traces of propionaldehyde were detected in pure cultures of strain Gö1.2Pd1 growing with 1,2-propanediol. Further subcultures of this strain on the same substrate did not grow any more but converted the substrate completely to propionaldehyde. Opened culture tubes spread a characteristic odor of mercaptanes which were probably formed chemically from the aldehydes produced and the sulfide used as reducing agent in the medium (Bayer 1954).

The observed effect of self-poisoning by propionaldehyde produced during 1,2-propanediol degradation could be avoided if the same strain was grown with this substrate $(5 \mathrm{mM})$ in continuous culture. With a mean residence time of $24 \mathrm{~h}\left(D=0.041 \mathrm{~h}^{-1}\right)$, no propionaldehyde was detected, and the substrate was completely converted to nearly equal amounts of propionate and propanol over more than 10 generations. Propionaldehyde was added to the medium reservoir in increasing steps up to $5 \mathrm{mM}$ final concentration and was converted to propionate and propanol as well. At higher concentrations, propionaldehyde inhibited growth of strain Gö1.2Pd1, and the typical smell of mercaptanes indicated that propionaldehyde was not completely degraded.

A marine strain growing with 1,2-diols, strain GraEtOH11, converted ethylene glycol to nearly equal

Table 2. Stoichiometry of primary alcohol oxidation by a syntrophic coculture of strain GraEtOH11 and Methanospirillum hungatei

\begin{tabular}{|c|c|c|c|c|c|c|}
\hline \multirow[t]{2}{*}{ Substrate } & \multirow{2}{*}{$\begin{array}{l}\text { Amount } \\
\text { of sub- } \\
\text { strate } \\
\text { supplied } \\
\text { ( } \mu \text { mol) }\end{array}$} & \multicolumn{5}{|c|}{ Products formed ( $\mu \mathrm{mol})$} \\
\hline & & $\begin{array}{l}\text { Meth- } \\
\text { ane }\end{array}$ & $\begin{array}{l}\text { Ace- } \\
\text { tate }\end{array}$ & $\begin{array}{l}\text { Propio- } \\
\text { nate }\end{array}$ & $\begin{array}{l}\text { Buty } \\
\text { rate }\end{array}$ & $\begin{array}{l}\text { Valer- } \\
\text { ate }\end{array}$ \\
\hline Ethanol & 250 & 125 & 240 & - & - & - \\
\hline Propanol $^{\mathrm{a}}$ & 250 & 126 & - & 248 & - & - \\
\hline Butanol $^{a}$ & 250 & 124 & - & - & 251 & - \\
\hline Pentanol $^{\mathrm{a}}$ & 250 & 125 & - & - & - & 260 \\
\hline
\end{tabular}

Experiments were carried out in $50 \mathrm{ml}$ serum bottles half-filled with culture medium and gassed with $\mathrm{N}_{2} / \mathrm{CO}_{2}$ gas mixture $(80 \% / 20 \%)$ a $5 \mathrm{mM}$ acetate was added as carbon source amounts of acetate and ethanol. In continuous culture at a residence time of $24 \mathrm{~h}\left(D=0.041 \mathrm{~h}^{-1}\right)$, increasing concentrations of acetaldehyde were added to a background of $10 \mathrm{mM}$ ethylene glycol. Strain GraEtOH11 degraded both ethylene glycol and acetaldehyde, the latter one up to $5 \mathrm{mM}$ concentration in the reservoir vessel. Nearly equal amounts of acetate and ethanol were formed; small concentrations of acetaldehyde were detected in the culture vessel at aldehyde concentrations higher than $5 \mathrm{mM}$ in the reservoir vessel. The results of the continuous culture experiments with strain GraEtOH11 are summarized in Table 3. It appears that acetaldehyde degradation supported growth of this strain at 1-4 $\mathrm{mM}$ acetaldehyde concentration. At higher concentrations, growth yields decreased due to acetaldehyde poisoning.

\section{Enzymes involved in 1,2-diol degradation}

Enzymes were assayed in crude cell extracts of ethylene glycol-grown cells of strain $\mathrm{CuAcl}$. The following activities were detected $\left(\mu \mathrm{mol}\right.$ substrate $\cdot \mathrm{min}^{-1} \cdot \mathrm{mg}$ protein $\left.{ }^{-1}\right)$ : alcohol dehydrogenase $(0.26)$, aldehyde dehydrogenase $(0.75)$, acetate kinase (0.85), and phosphate acetyltransferase (402). Diol dehydratase activity could not be detected in the strains of group III with the test systems applied, no matter if ethylene glycol, propanediol, or glycerol were used as substrates. Diol dehydratase activity was proven by the same methods in extracts of group I and group II isolates. It has to be assumed, therefore, that the diol dehydratase in the group III isolates is destroyed during cell homogenization by traces of oxygen or sodium ions transferred from the saltwater medium.

Alcohol dehydrogenase, aldehyde dehydrogenase, acetate kinase, and phosphate acetyl transferase were also detected in group I and group II isolates indicating that they were involved in energy metabolism in these isolates, too.

\section{Enumeration of alcohol-degrading bacteria}

Alcohol-degrading anaerobes were counted by the mostprobable-number technique with freshwater creek sediment and sewage sludge. With all four alcohols used as substrates - ethanol, ethylene glycol, propanol, and butanol numbers of alcchol degraders were by 1 to 2 orders of

Table 3. Growth yields and stoichiometry of substrate fermentation by strain GraEtOH11 growing with ethylene glycol and acetaldehyde in continuous culture

\begin{tabular}{lllllll}
\hline $\begin{array}{l}\text { Ethylene glycol supplied } \\
(\mathrm{mM})^{\mathrm{a}}\end{array}$ & $\begin{array}{l}\text { Acetaldehyde } \\
\text { supplied } \\
(\mathrm{mM})^{\mathrm{a}}\end{array}$ & $\begin{array}{l}\text { Acetaldehyde } \\
\text { detected } \\
(\mathrm{mM})^{\mathrm{b}}\end{array}$ & $\begin{array}{l}\text { Ethanol } \\
\text { formed } \\
(\mathrm{mM})^{\mathrm{b}}\end{array}$ & $\begin{array}{l}\text { Acetate } \\
\text { formed } \\
(\mathrm{mM})^{\mathrm{b}}\end{array}$ & $\begin{array}{l}\text { Optical } \\
\text { density } \\
\left(\mathrm{OD}_{650}\right)\end{array}$ & $\begin{array}{l}\text { Growth yield } \\
\mathrm{g} / \mathrm{mol} \text { total } \\
\text { substrate utilized }\end{array}$ \\
\hline 10.0 & - & - & 3.0 & 3.85 & 0.19 & 4.6 \\
10.0 & 1.0 & - & 4.35 & 5.07 & 0.24 & 5.3 \\
10.0 & 2.0 & - & 6.07 & 6.29 & 0.28 & 5.7 \\
10.0 & 3.0 & - & 6.87 & 7.35 & 0.32 & 6.36 \\
10.0 & 4.0 & - & 7.6 & 9.42 & 0.35 & 5.7 \\
10.0 & 5.0 & 1.57 & 7.44 & 9.0 & 0.27 & 4.1 \\
10.0 & 6.0 & & 7.71 & & \\
\hline
\end{tabular}

Experiments were carried out with $550 \mathrm{ml}$ fluid volume in the culture vessel and a mean residence time of $24 \mathrm{~h}_{(}\left(D=0.041 \mathrm{~h}^{-1}\right)$ as described in Materials and methods

${ }^{a}$ Substrate concentration in the reservoir vessel

${ }^{b}$ Concentrations measured in the culture vessel after equilibration for two volume changes following each step of increasing acetaldehyde concentration 
magnitude higher in creek sediment than in sewage sludge (Table 4).

The fermentation products were determined in all tubes to assess the metabolic types of bacteria involved in alcohol degradation. The results obtained with creek sediment are presented in Table 5. Ethanol was in all tubes nearly exclusively fermented to acetate and propionate, and methane was only a minor product. Degradation of ethylene glycol mainly led to acetate and methane, and propionate formation was less important. In two dilution ranges, free acetaldehyde appeared as product. In the first two tubes, acetate was nearly the only fermentation product. Propanol was oxidized to propionate; acetate appeared in the lower and methane in the higher dilutions as reduction product. Oxidation of butanol to butyrate was mainly coupled with formation of propionate in the higher dilution tubes; in the

Table 4. Most-probable-number enumerations of alcohol-degrading anaerobes in creek sediment and sewage sludge samples (cells per $\mathrm{ml})$

\begin{tabular}{lll}
\hline Substrate & Creek sediment & $\begin{array}{l}\text { Sewage } \\
\text { sludge }\end{array}$ \\
\hline Ethanol & $1.1 \cdot 10^{6}$ & $2.4 \cdot 10^{5}$ \\
Ethylene glycol & $4.6 \cdot 10^{6}$ & $4.6 \cdot 10^{3}$ \\
Propanol & $4.6 \cdot 10^{6}$ & $4.6 \cdot 10^{3}$ \\
Butanol & $1.1 \cdot 10^{7}$ & $1.1 \cdot 10^{4}$ \\
\hline
\end{tabular}

Enumerations were carried out in $17 \mathrm{ml}$ Bellco tubes closed with butyl rubber septa. Every tube contained $10 \mathrm{ml}$ of medium with $10 \mathrm{mM}$ substrate under a headspace of $80 \% \mathrm{~N}_{2} / 20 \% \mathrm{CO}_{2}$. Tubes were incubated at $28^{\circ} \mathrm{C}$ for $3-4$ weeks before evaluation. Optical densities higher than $\mathrm{OD}_{650}=0.05$ were taken as positive lower dilutions, most of the butyrate formed was further oxidized to acetate with concomitant methane formation.

Analyses of fermentation products in sewage sludge enumeration series gave basically similar results, except that syntrophic methanogenic alcohol oxidation usually predominated over acidogenic fermentation in the last positive dilution tubes (not shown). It can be summarized that acetate and propionate were important reduced end products of alcohol oxidation in the two freshwater samples examined, and that these acidogenic fermentations usually outcompeted methanogenic alcohol oxidation in the lower dilution tubes.

\section{Discussion}

In the present study, primary aliphatic alcohols and diols were used for enrichment and isolation of anaerobic fermenting bacteria from freshwater and marine sources. On the basis of cytological and physiological properties, these isolates were arranged into three different groups of bacteria: (i) homoacetogenic bacteria, (ii) bacteria forming propionate as reduced end product, and (iii) bacteria disproportionating diols and acetoin to fatty acids and primary alcohols. Whereas the first two types were exclusively isolated from freshwater sources including sewage sludge, the latter type was isolated from marine sources. The group I isolates can be attributed to the recently described species Acetobacterium carbinolicum (Eichler and Schink 1984) which differs from $A$. woodii and $A$. wieringae by its ability to oxidize primary alcohols to the respective fatty acids with concomitant formation of acetate as reduced product. The group II isolates are similar to the species Pelobacter propionicus (Schink 1984) which was originally isolated with

Table 5. Products formed after 4 weeks of incubation in most-probable-number enumeration tubes inoculated with creek sediment

\begin{tabular}{|c|c|c|c|c|c|c|c|}
\hline \multirow{3}{*}{$\begin{array}{l}\text { Inocolum } \\
\text { (m1) }\end{array}$} & \multicolumn{7}{|c|}{ Products formed $(\mathrm{mM})$ from $10 \mathrm{mM}$ substrate } \\
\hline & \multicolumn{3}{|c|}{ Ethanol as substrate } & \multicolumn{4}{|c|}{ Ethylene glycol as substrate } \\
\hline & Methane $^{a}$ & Acetate & Propionate & Methane & Acetate & Propionate & \\
\hline $10^{-1}$ & 1.1 & 3.4 & 2.8 & 0.6 & 9.4 & 1.3 & \\
\hline $10^{-2}$ & 0.3 & 5.1 & 4.9 & 0.14 & 11.2 & 1.9 & \\
\hline $10^{-3}$ & 0.5 & 3.9 & 4.7 & 2.7 & 8.8 & 1.4 & \\
\hline $10^{-4}$ & 0.7 & 4.2 & 5.0 & 2.2 & 8.8 & $1.6^{\mathrm{c}}$ & \\
\hline $10^{-5}$ & 0.2 & 4.0 & 5.6 & 3.1 & 7.8 & $1.3^{\mathrm{c}}$ & \\
\hline $10^{-6}$ & 1.7 & 4.6 & 4.3 & 3.2 & 8.0 & 1.2 & \\
\hline \multirow[t]{3}{*}{$10^{-7}$} & $-\mathbf{b}$ & $-{ }^{b}$ & $-{ }^{b}$ & 0.9 & 8.1 & 0.8 & \\
\hline & \multicolumn{3}{|c|}{ Propanol as substrate } & \multicolumn{4}{|c|}{ Butanol as substrate } \\
\hline & Methane & Acetate & Propionate & Methane & Acetate & Propionate & Butyrate \\
\hline $10^{-1}$ & 0.5 & 3.9 & 9.2 & 4.7 & 14.4 & 2.4 & 0.2 \\
\hline $10^{-2}$ & 0.4 & 3.8 & 10.9 & 2.0 & 12.7 & 3.0 & 0.2 \\
\hline $10^{-3}$ & 0.1 & 3.9 & 8.4 & 1.8 & 12.5 & 3.6 & 1.6 \\
\hline $10^{-4}$ & 3.3 & 1.2 & 10.3 & 1.2 & 0.5 & 4.0 & 7.7 \\
\hline $10^{-5}$ & 3.9 & 1.7 & 7.5 & 0.7 & 0.5 & 3.9 & 7.6 \\
\hline $10^{-6}$ & 2.8 & 1.7 & 5.9 & 0.9 & 0.5 & 4.0 & 8.5 \\
\hline $10^{-7}$ & 1.0 & 1.6 & 5.8 & 5.6 & 0.5 & 0.2 & 7.8 \\
\hline
\end{tabular}

All figures represent means of all positive tubes in the respective dilution range

a Methane was determined in the culture headspaces and calculated over the liquid culture volume

${ }^{\mathrm{b}}$ No growth detected

c In these tubes also traces of acetaldehyde and ethylmercaptane were detected 
2,3-butanediol as substrate. The group III isolates resemble Pelobacter carbinolicus (Schink 1984) which was isolated with 2,3-butanediol from marine sources and differs from the metabolically similar species $P$. venetianus (Schink and Stieb 1983) by its inability to degrade polyethylene glycol. Although the substrate utilization spectra of the three groups are rather different (Table 1) some general conclusions can be drawn. The group I isolates use, among others, sugars and one carbon compounds for growth, and are also able to demethylate betaine in a similar manner as methylamines are demethylated by methanol-utilizing methanogens (Hippe et al. 1979). The group II isolates are characterized by their ability to reductively carboxylate $\mathrm{C}_{2}$ compounds and form propionate as reduced end product. The formation of propionate from ethanol was first reported for a mixed culture (Samain et al. 1982) and was also observed with Desulfobulbus propionicus in the absence of sulfate (Laanbroek et al. 1982). In D. propionicus, propionate formation from lactate takes the classical randomizing pathway via succinate (Stams et al. 1984), and studies in our laboratory reveal that this is also true for propionate formation by $P$. propionicus. This metabolic type represents an interesting alternative to homoacetogenic acetate formation as a further means of using carbon dioxide as electron acceptor in anoxic environments. Consequently, one could call this new reaction type "homopropionate fermentation". Similar to homoacetate fermentation (Andreesen et al. 1970; Eichler and Schink 1984), this term does not necessarily mean that propionate is the only fermentation product but that is is formed by dissimilatory carbon dioxide reduction. The group III isolates are unable to use primary aliphatic alcohols for growth in pure culture. They disproportionate 1,2-diols, 2,3-butanediol, and acetoin to primary alcohols and fatty acids, and convert glycerol in the same manner to 1,3propanediol and 3-hydroxypropionate. Ethanolamine and choline are fermented to acetate and ethanol with concomitant formation of ammonia and trimethylamine, respectively. The biochemical pathways involved in the metabolism of this group of isolates were studied in some detail.

Alcohol dehydrogenase, coenzyme A-dependent aldehyde dehydrogenase, acetate kinase and phosphate acetyltransferase were measured in crude cell extracts of strain $\mathrm{CuAc1}$ grown with ethylene glycol, and exhibited activities high enough for involvement in dissimilatory metabolism. Unfortunately, a diol dehydratase transforming ethylene glycol to acetaldehyde could not be detected by the usual methods. Since diol dehydratases are known to be often sensitive to sodium ions (Toraya and Fukui 1982; Schütz and Radler 1984) we assume that sodium ions present in the crude extract of our marine isolates inhibited or inactivated this enzyme. The involvement of acetaldehyde in diol degradation was proven by (i) intermediary aldehyde accumulation during diol degradation and (ii) growth with acetaldehyde at sublethal concentrations in continuous culture. A scheme of energy metabolism of this type of isolates is presented in Fig. 3.

It appears probable that ethanolamine and choline are metabolized in a similar manner by a coenzyme $\mathrm{B}_{12}$-dependent shift reaction. Conversion of these two substrates to acetate and ethanol or acetate alone has been published repeatedly (Hayward and Stadtman 1959; Bradbeer 1965; Fiebig and Gottschalk 1983).

The group III isolates were also able to oxidize primary aliphatic alcohols to the respective fatty acids in syntrophic

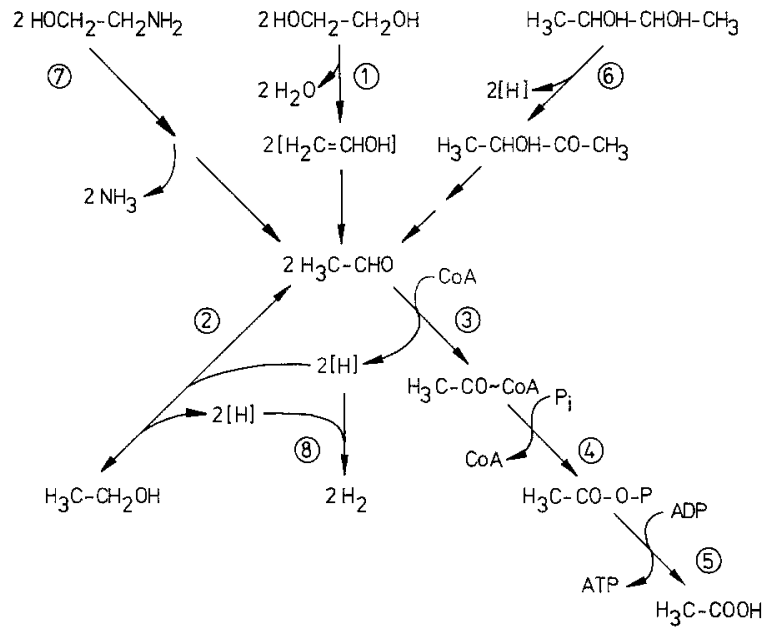

Fig. 3. Scheme of energy metabolism by Pelobacter carbinolicus. Enzymes involved: 1 Diol dehydratase, 2 alcohol dehydrogenase, 3 aldehyde dehydrogenase, 4 phosphate acetyltransferase, 5 acetate kinase, 6 2,3-butanediol dehydrogenase, 7 ethanolamine ammonia lyase, 8 hydrogenase. Enzymes 2, 4, 5, 6, 8 were measured with strain GraBd1 (Schink 1984), enzymes 2, 3, 4, 5 with strain CuAc1 in the present study

association with hydrogen-oxidizing anaerobes, e.g. homoacetogens or methanogens. Moreover, 1,2-diols could be used for separation of syntrophic acetate-forming binary associations of disproportionating and homoacetogenic bacteria. Therefore, 1,2-diols as well as 2,3-butanediol and acetoin are suited substrates for pure culture cultivation of these interesting bacteria which serve the role of the classical "S-organism" in Barker's "Methanobacillus omelianskii" (Bryant et al. 1967). Our studies demonstrate that various S-organisms exist in nature, and that substrates that are transformed to aldehydes are suited for their isolation. Studies are in progress in our laboratory to investigate kinetic and energetic aspects of syntrophic alcohol oxidation in mixed and pure culture experiments with these isolates.

In freshwater environments, syntrophic methanogenic mixed associations have to compete in primary alcohol degradation with fermentative bacteria metabolically similar to our isolate groups I and II. The free energy changes of the reactions underlying the respective fermentation processes are rather similar (Schink et al. 1985), and bacteria of groups I and II appear to outcompete syntrophic systems at enhanced substrate concentrations. Thus, these two types of bacteria were exclusively isolated from freshwater sources, and homoacetogenesis and homopropionate fermentation also predominated in the lower dilution tubes in our enumeration experiments (Table 6). Perhaps the slight acidification due to acid formation from the alcohol substrates helps to improve conditions for acidogenic fermentations in the first dilution tubes: homoacetogenic fermentations were found to outcompete methanogenic carbon dioxide reduction in a freshwater sediment at $\mathrm{pH} 6.1$ (Phelps and Zeikus 1984). Although propionate formation usually accounts for only a minor part of ethanol degradation in freshwater environments (Schink et al. 1985), propionate was the main reduced end product of ethanol and butanol degradation in our most-probable-number enumeration experiments, at least in the lower dilution tubes. Syntrophic methanogenic degradation predominated in enumerations with ethylene glycol. Unfortunately, no fresh marine sedi- 
ments were at hand to do comparative enumeration experiments with marine sediment samples. Apparently, propionate-forming ethanol degraders do not successfully compete with the other metabolic types in these environments, and syntrophic associations with homoacetogenic bacteria predominate in enrichments with primary alcohols as substrates.

Acknowledgements. The authors are greatly indebted to Prof. Dr. N. Pfennig for support and valuable discussions. This work was in part supported by a grant of the Deutsche Forschungsgemeinschaft.

\section{References}

Abeles RH (1966) Dioldehydrase. In: Colowick SP, Kaplan NO (eds) Methods in enzymology, vol 9. Academic Press, New York London, pp 686-689

Abeles RH, Lee HA, Jr (1961) An intramolecular oxidation reduction requiring a cobamide coenzyme. J Biol Chem 236:23472350

American Public Health Association (ed) (1969) Standard methods for the examination of water and wastewater including bottom sediments and sludge. New York, pp 604-609

Andreesen JR, Gottschalk G, Schlegel HG (1970) Clostridium formicoaceticum nov. spec. Isolation, description and distinction from C. aceticum and C. thermoaceticum. Arch Mikrobiol $72: 154-174$

Barker HA (1936) On the biochemistry of the methane fermentation. Arch Mikrobiol 7:404-419

Bayer O (1954) Sauerstoffverbindungen II. Teil 1. Aldehyde. In: Müller E (ed) Methoden der organischen Chemie (HoubenWeyl), Bd. 7,1. Thieme, Stuttgart, pp 449-451

Bergmeyer HU (1974) Methoden der enzymatischen Analyse, 3rd edn. Verlag Chemie, Weinheim

Bornstein BT, Barker HA (1948) The energy metabolism of Clostridium kluyveri and the synthesis of fatty acids. J Biol Chem 172:659-669

Bradbeer C (1965) The clostridial fermentations of choline and ethanolamine. J Biol Chem 240:4669-4674

Braun M, Mayer F, Gottschalk G (1981) Clostridium aceticum (Wieringa), a microorganism producing acetic acid from molecular hydrogen and carbon dioxide. Arch Microbiol 128:288293

Bryant MP, Wolin EA, Wolin MJ, Wolfe RS (1967) Methanobacillus omelianskii, a symbiotic association of two species of bacteria. Arch Mikrobiol 59:20-31

Bryant MP, Campbell LL, Reddy CA, Crabill MR (1977) Growth of Desulfovibrio in lactate or ethanol media low in sulfate in association with $\mathrm{H}_{2}$-utilizing methanogenic bacteria. Appl Environ Microbiol 33:1162-1169

Eichler B, Schink B (1984) Oxidation of primary aliphatic alcohols by Acetobacterium carbinolicum sp. nov., a homoacetogenic anaerobe. Arch Microbiol 140:147-152

Fiebig K, Gottschalk G (1983) Methanogenesis from choline by a coculture of Desulfovibrio sp. and Methanosarcina barkeri. Appl Environ Microbiol 45:161-168

Gaston LW, Stadtman ER (1963) Fermentation of ethylene glycol by Clostridium glycolicum sp. n. J Bacteriol 85:356-362

Goa J (1953) A microbiuret method for protein determination; determination of total protein in cerebrospinal fluid. Scand $J$ Clin Lab Invest 5:218-222

Hayward HR, Stadtman TC (1959) Anaerobic degradation of choline. I. Fermentation of choline by an anaerobic, cytochrome-producing bacterium, Vibrio cholinicus n. sp. J Bacteriol $78: 557-561$

Hippe H, Caspari D, Fiebig K, Gottschalk G (1979) Utilization of trimethylamine and other $\mathrm{N}$-methyl-compounds for growth and methane formation by Methanosarcina barkeri. Proc Natl Acad Sci USA 76:494-- 498
Kuenen JG, Veldkamp H (1972) Thiomicrospira pelophila nov. gen., nov. sp., a new obligately chemolithotrophic colourless sulfur bacterium. Antonie van Leeuwenhoek J Microbiol Serol $38: 241-256$

Laanbroek HJ, Abee T, Voogd JL (1982) Alcohol conversion by Desulfobulbus propionicus Lindhorst in the presence and absence of sulfate and hydrogen. Arch Microbiol 133:178-184

Oberlies G, Fuchs G, Thauer RK (1980) Acetate thiokinase and the assimilation of acetate in Methanobacterium thermoautotrophicum. Arch Microbiol 128:248-252

Odom JM, Peck HD (1981) Localization of dehydrogenases, reductases and electron transfer components in the sulfate-reducing bacterium Desulfovibrio gigas. J Bacteriol 147:161 - 169

Pfennig N (1978) Rhodocyclus purpureus gen. nov. and sp. nov., a ring-shaped, vitamin $\mathrm{B}_{12}$-requiring member of the family Rhodospirillaceae. Int J Syst Bacteriol 28:283-288

Phelps TJ, Zeikus JG (1984) Influence of pH on terminal carbon metabolism in anoxic sediments from a mildly acidic lake. Appl Environ Microbiol (in press)

Postgate JR, Campbell LL (1966) Classification of Desulfovibrio species, the nonsporulating sulfate-reducing bacteria. Bacteriol Rev 30:732-738

Samain E, Albaniac G, Dubourgier HC, Touzel JP (1982) Characterization of a new propionic acid bacterium that ferments ethanol and displays a growth factor dependent association with a Gram negative homoacetogen. FEMS Microbiol Lett 15:69-74

Schink B (1984) Fermentation of 2,3-butanediol by Pelobacter carbinolicus $\mathrm{sp}$. nov. and Pelobacter propionicus, sp. nov., and evidence for propionate formation from $\mathrm{C}_{2}$ compounds. Arch Microbiol 137:33-41

Schink B, Pfennig N (1982) Fermentation of trihydroxybenzenes by Pelobacter acidigallici gen. nov. sp. nov., a new strictly anaerobic, non-sporeforming bacterium. Arch Microbiol 133:195201

Schink B, Stieb M (1983) Fermentative degradation of polyethylene glycol by a new, strictly anaerobic, Gram negative, nonsporeforming bacterium, Pelobacter venetianus sp. nov. Appl Environ Microbiol 45:1905-1913

Schink B, Phelps TJ, Eichler B, Zeikus JG (1985) Comparison of ethanol degradation pathways in anoxic freshwater environments. J Gen Microbiol 131:651 - 660

Schütz H, Radler F (1984) Propanediol-1,2-dehydratase and metabolism of glycerol of Lactobacillus brevis. Arch Microbiol $139: 366-370$

Stams AJM, Kremer DR, Nicolay K, Hansen TA (1984) Pathway of propionate formation in Desulfobulbus propionicus. Arch Microbiol 139:167-173

Thauer RK, Jungermann K, Decker K (1977) Energy conservation in chemotrophic anaerobic bacteria. Bacteriol Rev 41:100180

Toraya T, Fukui S (1982) Diol Dehydrase. In: Dolphin D (ed) $\mathbf{B}_{12}$, vol 2. John Wiley and Sons, New York, pp 233-262

Toraya T, Honda S, Fukui S (1979) Fermentation of 1,2-propanediol and 1,2-ethanediol by some genera of Enterobacteriaceae, involving coenzyme $\mathrm{B}_{12}$-dependent diol dehydratase. I Bacteriol 139:39 - 47

Tschech A, Pfennig N (1984) Growth yield increase linked to caffeate reduction in Acetobacterium woodii. Arch Microbiol 137:163-167

Widdel F, Pfennig N (1981) Studies on dissimilatory sulfate-reducing bacteria that decompose fatty acids. I. Isolation of new sulfate-reducing bacteria enriched with acetate from saline environments. Description of Desulfobacter postgatei gen. nov. sp. nov. Arch Microbiol 129:395-400

Wieringa KT (1940) The formation of acetic acid from carbon dioxide and hydrogen by anaerobic spore-forming bacteria. Antonie van Leeuwenhoek J Microbiol Serol 6:251 -262

Received February 8, 1985/Accepted June 25, 1985 